\title{
Fracture Resistance of Endodontically Treated Teeth Restored With Lithium Disilicate Crowns Retained With Fiber Posts Compared To Lithium Disilicate and Cerasmart Endocrowns: In Vitro Study
}

Saleh Al-shibri and Jylan Elguindy*

Fixed Prosthodontics Department, Cairo University, Egypt

*Corresponding author: Jylan Elguindy, Professor of Fixed Prosthodontics, Cairo university, Giza, Cairo, Egypt, Tel:+201100115007; E-mail: dr jul@hotmail.com Received date: October 26, 2017; Accepted date: November 07, 2017; Published date: November 14, 2017

Copyright: @ 2017 Al-shibri S, et al. This is an open-access article distributed under the terms of the Creative Commons Attribution License, which permits unrestricted use, distribution, and reproduction in any medium, provided the original author and source are credited.

\begin{abstract}
Purpose: The purpose of this in vitro study was to compare the effect of endocrowns and glass fiber postretained crowns on the fracture resistance of endodontically treated maxillary premolars made of different ceramics materials.

Materials and Methods: Thirty sound maxillary premolars were endodontically treated. They were randomly assigned into 3 groups $(n=10)$, in which, teeth were prepared to receive all- ceramic restorations. GP: fiber post and resin core and ferrule with all-ceramic (IPS E-max CAD, Ivoclar-Vivadent) conventional crown. GE: Endocrown with butt joint finish line design made of (IPS E-max CAD, Ivoclar-Vivadent). GC: Endocrown with butt joint finish line design made of hybrid nanoceramic (CERASMART, GC Dental, USA). The lithium disilicate (IPS E-max press, Ivoclar-Vivadent) and hybrid nanoceramic (CERASMART, GC Dental, USA) all-ceramic restorations were made by CAD/CAM system (CEREC MC XL SW 4.0) and adhesively cemented with dual-cure resin cement (BisCem Bisco, Inc, USA). Specimens were mounted in a universal testing machine (Model 3345; Instron Industrial Products, Norwood, MA, USA). Each specimen was loaded to failure at a crosshead speed of $5.0 \mathrm{~mm} / \mathrm{min}$. Mode of failure was also examined. Data were analyzed using one way analysis of variance (ANOVA) and Tukey's post hoc significance difference tests. Differences were considered significant at $\mathrm{P}<0.05$.
\end{abstract}

Results: One way ANOVA test showed that group $(G C)$ recorded statistically significant $(p<0.05)$ highest mean value $(1522.64 \mathrm{~N})$ followed by group (GP) (1301.34 N) then group (GE) (725.73 N). Group (GE) recorded the lowest statistically significant $(p<0.05)$ mean value $(725.73 \pm 137.89 \mathrm{~N})$. Pair-wise Tukey's post-hoc test showed nonsignificant $(P>0.05)$ difference between GP and GC groups.

Conclusions: Within the limitations of this study, all fracture resistance loads obtained in this study were far beyond the maximum masticatory forces and the presence of hybrid nanoceramic increased the fracture resistance of endodontically treated maxillary premolars restored with endocrown than those restored with lithium disilicate endocrowns, in failure mode hybrid nanoceramic showed favorable fracture pattern than lithium disilicate.

Keywords: Endocrown; Lithium Disilicate; Hybrid Ceramic; Cerasmart; CAD/CAM; Fiber Post; Fracture Resistance

\section{Introduction}

Rehabilitation of endodontically treated teeth with large coronal destruction is still a clinical challenge, especially due to the loss of strength characteristics associated to the removal of pulp and surrounding dentin tissues. Coronal retention of the restoration is usually compromised, thus intraradicular posts combined or not with core materials may be required. Despite all clinical success achieved with the use of intraradicular posts, one disadvantage of this system is the additional removal of sound tissue needed for fitting the post into the root canal; additionally, this procedure was revealed to affect the overall biomechanical behavior of the restored teeth. Alternatively, other restorative approaches have been suggested, including but not limited to the well-known endocrown restorations [1-3].

Endocrowns assemble the intraradicular post, the core, and the crown in one component, thus representing monoblock restorations.
Different from conventional approaches using intraradicular posts, endocrown restorations are anchored to the internal portion of the pulp chamber and on the cavity margins, thereby resulting in both macro- and micro mechanical retention, provided by the pulpal walls and adhesive cementation, respectively. In addition, endocrowns have the advantage of removing lower amounts of sound tissue compared to other techniques, and with much lower chair time needed.

Also, the masticatory stresses received at the tooth/restoration interface are more properly dissipated along the overall restored tooth structure when endocrowns are placed. Depending on the material chosen, ceramic or resin composites, the system may become more rigid than the dental structure (in case of ceramics) or biomechanically similar to the tooth (in case of resin composites) [4-6].

The type of material may also have influence on the performance of endocrowns, with wide collection of ceramic material has been available for CAD/CAM technology, ranging from weak feldspathic ceramic and Lucite glass ceramic to high-strength lithium disilicate glass ceramic and zirconium oxide. Most recently, a resin nanoceramic has been introduced for permanent CAD/CAM fabricated 
Citation: Al-shibri S, Elguindy J (2017) Fracture Resistance of Endodontically Treated Teeth Restored With Lithium Disilicate Crowns Retained With Fiber Posts Compared To Lithium Disilicate and Cerasmart Endocrowns: In Vitro Study. Dentistry 7: 464. doi: $10.4172 / 2161-1122.1000464$

Page 2 of 9

restorations. Ultrastructure and mechanical properties of available CAD/CAM material vary widely, their and, accordingly, their mechanical behavior in the tooth restoration complex is expected to vary as well. With the intent of increasing the amount of information about the behavior of these material when used for endocrowns, I was found worth to evaluate the fracture resistance, and the failure modes of CERASMART and E.max CAD endocrowns restoration compared with conventional crowns retained by glass fiber posts and core of maxillary premolars teeth when compressive force was applied $[7,8]$.

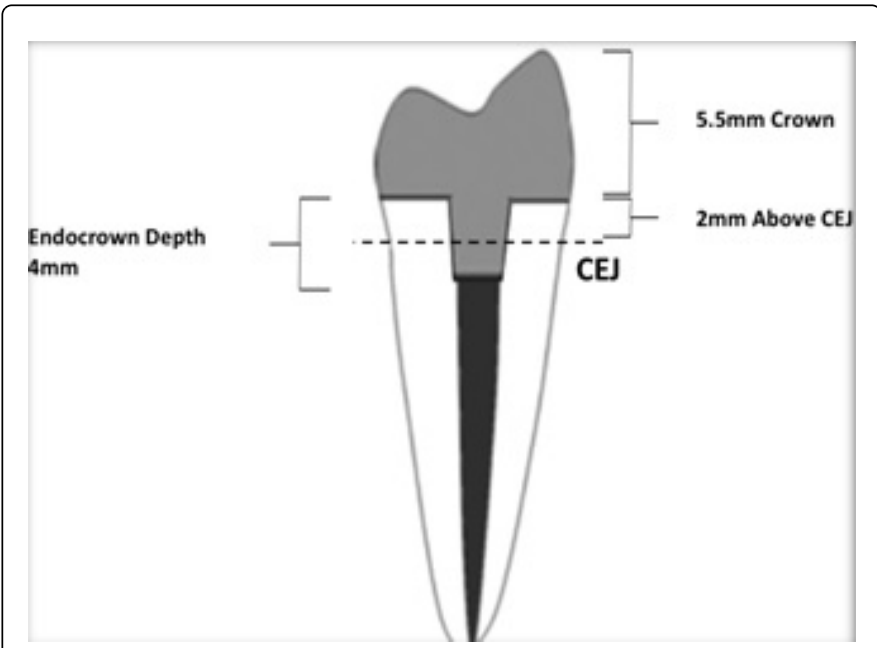

Figure 1: Schematic diagram illustration Endocrowns preparation design.

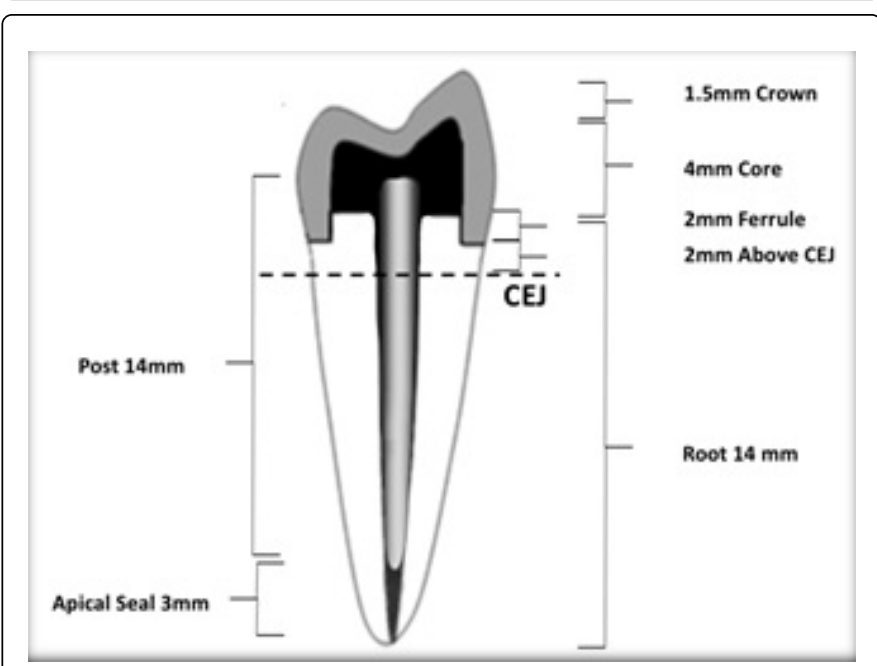

Figure 2: Schematic diagram illustration post \& core the preparation with $2 \mathrm{~mm}$ ferrule.

Endocrowns were revealed to fail more when fixed to premolars, probably due to their smaller adhesion area and greater crown height compared to molars. In addition, premolars receive more horizontally (non-axial) directed forces than molars, which may also influence fracture resistance [9]. Strong bonding between the indirect restoration and tooth structure increases the durability and longevity of the prosthesis [10]. The influence of different crown material on fracture resistance of ceramic crowns placed on endodontically treated maxillary premolars has not been clearly established. In this vitro study, there were two-null hypothesis, the first; Endocrowns would have more fracture resistance than IPS e.max CAD crowns retained with fiber posts and composite core, the second; Endocrowns restoration made of hybrid ceramics CERASMART material would show more fracture resistance than endocrowns made of IPS e.max CAD (Figures 1 and 2).

\section{Materials and Methods}

\section{Teeth selection}

Thirty caries free of recently extracted human maxillary premolars were selected for the study. The teeth were inspected under high light condition with magnifying lens ( $2^{*}$ magnification). The anatomic crowns were selected to be with average dimensions after measuring the bucco-lingual $(9 \pm 1 \mathrm{~mm})$ and mesio-distal $(7 \pm 0.5 \mathrm{~mm})$ using a caliper (MarCal 16 DN, Germany).

\section{Teeth mounting}

All teeth were mounted in epoxy resin block using a custom-made round teflon shape sample holder $(2 \mathrm{~cm}$ length, $2 \mathrm{~cm}$ internal diameters) in a vertical direction using parallel meter, teeth are embedded in the epoxy resin block up to $2 \mathrm{~mm}$ below the CEJ (simulated bone level) and hold in position till complete polymerization of the resin.

\section{Preparation of the teeth}

Decapitation of teeth: The crowns of the collected teeth were removed $2 \mathrm{~mm}$ above the cemento-enamel junction from the proximal surfaces using a diamond disc and a sufficient coolant. After crowns separation sample teeth, were stored in $0.9 \%$ sterile saline solution to avoid dryness.

Endodontic treatment: The access cavities of the teeth were performed a round bur followed by an ENDO-Z bur (Dentsply, Switzerland) using high speed hand piece under copious water coolant. The working length of each tooth determined by using K-file size 15 with radiograph than teeth canals were treated using rotary system $\mathrm{Ni}$ Ti (Protaper, Dentsply, Switzerland) with lubricant (MD-Chelcream, METABIOMED, Korea) till files size F3 with working length $1 \mathrm{~mm}$ before apical foramen with irrigation using sodium hypochlorite $4.2 \%$ in between files, after intermittent irrigation, the root canals were dried with paper points.

With matched tapered single cone (Dentsply, Switzerland) obturation technique. A size F3 master cone was tried to fit the prepared canal and reaching the full working length with tug-back action.

Gutta-percha point were coated with resin sealer (ADSEAL, MetaBiomed, korea) and placed in root canal till to the working length. Excess gutta-precha was removed using heated instrument (cherry red) and the coronal part was compacted with a plunger vertically.

\section{Classification of the samples}

The teeth were randomly divided in to 3 main groups (10n) in each group, according to the type of restoration and material used as shown in Table 1: 
Citation: Al-shibri S, Elguindy J (2017) Fracture Resistance of Endodontically Treated Teeth Restored With Lithium Disilicate Crowns Retained With Fiber Posts Compared To Lithium Disilicate and Cerasmart Endocrowns: In Vitro Study. Dentistry 7: 464. doi: $10.4172 / 2161-1122.1000464$

Page 3 of 9

Group (GP): Endodontically treated teeth with $2 \mathrm{~mm}$ ferrule effect restored with glass fiber posts retained lithium disilicate crowns.

Group (GE): Endodontically treated teeth restored with Lithium disilicate endo-crowns with butt joint finish line.

Group (GS): Endodontically treated teeth restored with Hybrid ceramic (CERASMART) endo-crowns with butt joint finish line.

\section{Allocation concealment mechanism}

The samples were numbered from 1-30 and written on folded paper then placed in opaque sealed envelopes.

Implementation: All steps of sample selection, randomization and preparation was assigned by the candidate under supervision.

Blinding: Was done by assessor (technician).

Randomization: All samples were numbered from 1 and ascending to 30 and then were divided by the web site by www.randomizer.org into 3 equal groups.

\section{Preparation design}

GP (Post and core supported crowns): The ten teeth of group GP received glass fiber posts size no.2 (Nordin Glassix+plus fiber post, Switzerland) and a light cure resin composite filling core (Light-Core, Bisco Inc, USA). After coronal sectioning, the gutta-percha was removed from palatal canal using a pilot reamer of the post system to the length of $11 \mathrm{~mm}$ from the preparation margins. Each glass fiber post was reduced to length of $14 \mathrm{~mm}$ by cutting the coronal end with diamond separating disc, resulting in a dowel extending $3 \mathrm{~mm}$ above the coronal surface of the trimmed crown.

A post space was prepared with the corresponding calibrating drill (size no.2) included in the post system. The canals were etched with $37 \%$ phosphoric acid (ETCH-37 w/BAC, Bisco Inc, USA) for 15 seconds. The canals were thoroughly rinsed with water, dried with compressed air and paper points.

A light cure adhesive agent (All-Bond Universal, Bisco, Inc, USA) was applied inside the root canal using a micro brush. The adhesive was rubbed to canal walls for 10 seconds and the excess solvent was removed with gentle oil free compressed air for 1-3 seconds and light cured for 20 seconds according to manufacturer instructions.

Using a microbrush, silane coupling agent (Porcelain Primer/BisSilane, Bisco, Inc, USA) was applied on the post surface for one $60 \mathrm{sec}$ and then gently air dried for 5 seconds. The post was luted with dual cure resin cement BisCem (Biscem, Bisco Inc, USA) were auto mixed and applied along the post surface and inside the post space canal. The post inserted, then positioned in place after up and down motion to ovoid air bubbles formation. The post was positioned in place with a frim finger pressure, then the excess resin cement was removed with a microbrush, followed by light curing for 20 seconds from occlusal surface.

Composite core construction: The core build up (Light-C, Bisco Inc, USA) was made by injecting desired amount of Light-Core Composite injected the around the post and into transparent celluloid crown which then placed over the post to allow for shape standardization between samples. Light cure was for 20 seconds done for each surface.

Ferrule preparation: Using a special milling machine (PARASKOP M MILLING UNIT USA) incorporated with conventional-speed straight hand-piece perpendicular to surveyor platform, Teeth were prepared with $2 \mathrm{~mm}$ circumferential ferrule axial wall heights, and with 10 o convergence. All axial walls had circumferential 90o shoulder margin $1 \mathrm{~mm}$ wide with rounded internal line angle, the teeth were further. The height of the prepared teeth was $6 \mathrm{~mm}$ from the finish line to the buccal cusp ( $2 \mathrm{~mm}$ ferrule, $4 \mathrm{~mm}$ core) and $5 \mathrm{~mm}$ from finish line to the central groove of occlusion ( $2 \mathrm{~mm}$ ferrule, $3 \mathrm{~mm}$ core).

\section{GE and GS (IPS e.max CAD and CERASMART, Endocrowns)}

After coronal sectioning to prepare a circular butt margin, gutta percha was removed till canals entrance with no more drilling inside the canals, a thin layer of flowable composite material (Filtek Z350, 3M ESPE Dental products, St. Paul, USA) was bonded to seal the canal entrance and to enhance the bonding of the ceramics endocrowns constructed in later stage.

The pulp chamber was prepared to eliminate undercuts with a $10 \mathrm{o}$ coronal divergence, with an oval shape and a depth of $4 \mathrm{~mm}$ from the cavosurface margin with all internal line angles were rounded and smooth 11 using a special milling machine incorporated with conventional-speed straight hand-piece perpendicular to surveyor platform. The internal line angles were rounded and smooth (Figures 3,4 and 5).

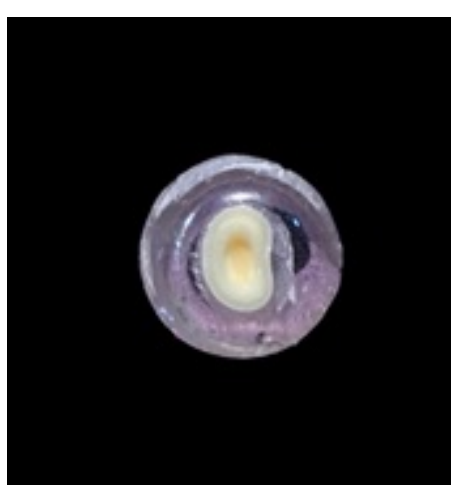

Figure 3: Endocrown preparation.

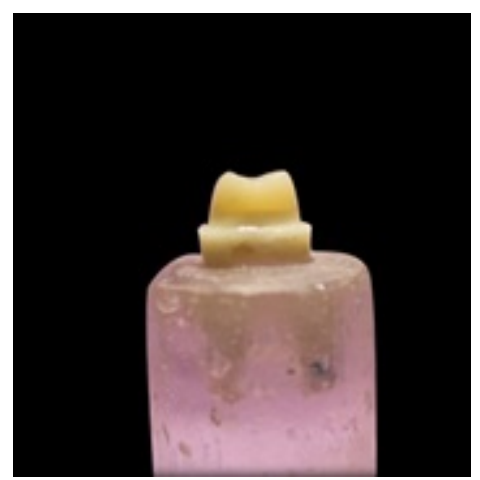

Figure 4: Post and core the preparation. 
Citation: Al-shibri S, Elguindy J (2017) Fracture Resistance of Endodontically Treated Teeth Restored With Lithium Disilicate Crowns Retained With Fiber Posts Compared To Lithium Disilicate and Cerasmart Endocrowns: In Vitro Study. Dentistry 7: 464. doi: $10.4172 / 2161-1122.1000464$

Page 4 of 9

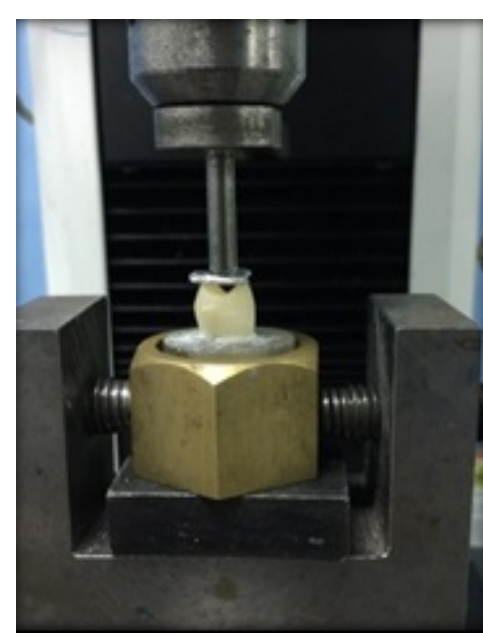

Figure 5: Tin foil was placed between the tooth and the loading stainless steel tip.

\section{Construction of Cerec CAD/CAM endocrowns and crowns}

A CAD/CAM system (CEREC MC XL SW 4.0) was used for the fabrication of all samples in this study.

Scanning and designing for all groups: To obtain a threedimensional image for each prepared tooth on the computer screen of the Cerec CAD/CAM (CEREC MC XL SW 4.0) software system the prepared tooth was scanned using Omnicam scanner, then the captured picture was saved in preparation catalogue of software. The software calculated a virtual model from the scanned pictures and automatic margin finder was used for preparation margin detection. With the aid of Cerec (CEREC MC XL SW 4.0) software the scanned prepared teeth was correlated to a virtual endocrowns restoration with $5.5 \mathrm{~mm}$ buccal cusp height and $5 \mathrm{~mm}$ lingual cusp height in order to standardized tooth from with $80 \mathrm{~m} \mu$ cement space, while full crowns had $1.5 \mathrm{~mm}$ thickness

Milling process for all groups: To start the milling procedure, the type of the block (IPS e.max CAD or CERASMART Block) as well as the size were selected and confirmed with "OK" button. The selected ceramic block of the required size was inserted in spindle of the milling chamber of the Cerec MC XL milling Machin and fastened with the set screw.

The milling process was fully automated without any interference with two diamond bures acting together simultaneously in the shaping process with copious water cooling sprayed from both directions. After completion of the milling process, the crowns were separated manually from the block holder with a diamond cutting instrument. All endocrowns and crowns were cheeked over there corresponding teeth for seating.

Crystallization and glaze firing only for GP and GE (IPS e.max CAD crowns and endo crowns): The Program at P300 furnace (Ivoclar Vivadent, Schaan, Liechtenstein) was used for crystallization and glaze firing. The IPS e.max CAD ceramic crowns appeared to be in their precrystallized from after milling where they have the bluish-gray color. Their crystallization process imparts the glass ceramic with its final strength and esthetic properties. The IPS e.max CAD ceramic crown were supported by an object fix material and fired on their special firing tray according to the manufacture's and fired on their maximum functional and esthetic properties. The starting temperature was $403^{\circ} \mathrm{C}$ and increased at rate of $90^{\circ} \mathrm{C} / \mathrm{min}$ until $890^{\circ} \mathrm{C}$ and hold for 2 minutes; then firing was increased at a rate of $30^{\circ} \mathrm{C} / \mathrm{min}$ until $840^{\circ} \mathrm{C}$ and hold for 7 minutes.

Finishing and polishing of CERASAMRT endocrowns: As CERASMART restorations do not need for firing as it hybrid ceramic, the restorations were finished using GC ultimate finishing and polishing kit (GC polishing kit America Inc USA) and Diapolisher paste (GC DiaPolisher Paste America Inc USA), which was applied with low hand speed. The luster quickly appeared as the restorations were polished.

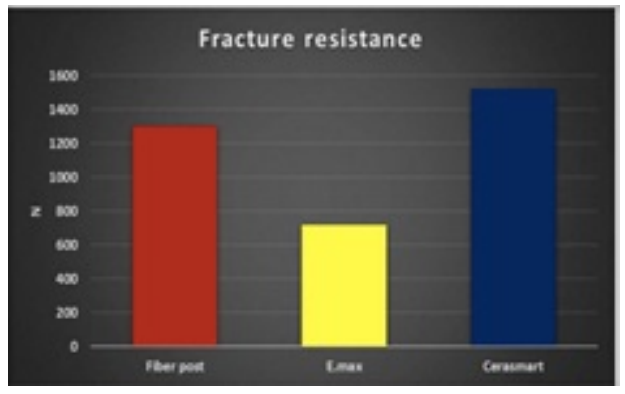

Figure 6: A column chart of fracture resistance mean values for group fiber post, E.max CAD endocrown and CERASMART endocrowns.

\section{Bonding procedures}

\section{Surface treatment of restorations}

IPS e.max CAD restorations (GP and GS): Intaglio surfaces of each endocrown and conventional crown were treated according to the manufacturer's instructions for the respective block material. Etching with 4\% hydrofluoric acid gel (Porcelain Etchant Gel- 4\% Buffered Hydrofluoric, Bisco Inc, USA) was applied for 20 seconds then rinsed for 60 seconds with running water and dried for 30 seconds with moisture-free air. A ceramic primer containing silane coupling agent (Porcelain Primer/Bis-Silane ${ }^{\mathrm{Tm}}$, Bisco Inc, USA) was applied to the intaglio surfaces of all endocrowns and allowed to dry for 60 seconds.

Cerasmart restoration (GS): Intaglio surfaces of each endocrown were treated according to the manufacturer's instructions. Etching with $4 \%$ hydrofluoric acid gel was applied for 20 seconds then rinsed for 60 seconds with running water and dried for 30 seconds with moisturefree air. A ceramic primer containing silane coupling agent was applied to the intaglio surfaces of all endocrowns and allowed to dry for 60 seconds.

Surface treatment of the prepared natural tooth: Prepared tooth surfaces were etched with $37 \%$ phosphoric acid-etching gel (ETCH-37 w/BAC, Bisco Inc, USA) for 15 seconds, rinsed for 20 seconds, and dried with oil-free air for another 5 seconds. Two separate coats of allbond (Universal ALL-BOND UNIVERSAL, Bisco Inc, USA), were applied to the preparation with a microbrush with no light curing between the coats. Excess solvent was then dried with oil-free air for 3 seconds, then light cured for 20 seconds. 
Citation: Al-shibri S, Elguindy J (2017) Fracture Resistance of Endodontically Treated Teeth Restored With Lithium Disilicate Crowns Retained With Fiber Posts Compared To Lithium Disilicate and Cerasmart Endocrowns: In Vitro Study. Dentistry 7: 464. doi: $10.4172 / 2161-1122.1000464$

Page 5 of 9

The dual cure resin cement BisCem cement (BisCem, Bisco Inc, USA) was applied on the prepared surface of teeth. Then each crown and endocrown was bonded to its corresponding tooth with finger pressure, excess cement was removed immediately with a microbrush. A customized loading device then used to apply constant load $3 \mathrm{Kg}$ parallel to the long axis of each restoration to prevent rebounding of the restoration during cementation, then light activated at each surface for 20 seconds according to manufacturer's instructions.

\section{Fracture resistance determination}

A single static compressive load application was applied along the long axis of each specimen, were individually mounted on a computer controlled materials using a universal testing machine (Model 3345; Instron Industrial Products, Norwood, MA, USA) with a loadcell of 5 $\mathrm{KN}$ and data were recorded using computer software (Instron ${ }^{\circledR}$ Bluehill Lite Software). Samples were secured to the lower fixed compartment of testing machine by tightening screws. Fracture test was done by compressive mode of load applied occlusally using a metallic rod with round tip (3.4 $\mathrm{mm}$ diameter) attached to the upper movable compartment of testing machine traveling at cross-head speed of 0.5 $\mathrm{mm} / \mathrm{min}$ with two layers foil sheet in-between to achieve homogenous stress distribution and minimization of the transmission of local force peaks. The load at failure manifested by an audible crack and confirmed by a sharp drop at load-deflection curve recorded using computer software (Bluehill Lite Software Instron ${ }^{\infty}$ Instruments). The load required to fracture was recorded in Newton. (Figures 4, 5 and 6) Data recorded were collected, tabulated and statically analyzed.

\section{Fracture mode}

Following the fracture resistance test, fracture mode all samples were examined visually and photographically using a digital camera (Canon D600). The specimens were inspected to determine different fracture modes whether favorable (repairable) or unfavorable (irreparable) the failure was considered unfavorable if the tooth fracture was below the CEJ including vertical root fracture. In other hand, favorable fracture was defined as restorable failure above CEJ (Tables 1 and 2).

\begin{tabular}{|l|l|l|l|l|l|l|}
\hline \multicolumn{3}{|l|}{ Descriptive Statistics } & \multicolumn{3}{l|}{} \\
\hline \multirow{2}{*}{ E.max CAD } & Groups & N & Minimum & Maximum & Mean & Std.Deviation \\
\cline { 2 - 8 } & GP (Post) & 10 & 1068.51 & 1611.32 & 1301.34 & \pm 177.12 \\
\cline { 2 - 9 } & GE (Endocrowns) & 10 & 428.54 & 914.83 & 717.33 & \pm 198.59 \\
\hline CERASMART & GS (Endocrowns) & 10 & 930.62 & 1871.19 & 1522.64 & \pm 352.52 \\
\hline
\end{tabular}

Table 1: Descriptive statistics of all groups.

\begin{tabular}{|c|c|c|c|c|}
\hline \multirow{3}{*}{ Study Groups } & \multicolumn{4}{|c|}{ Fracture MODE } \\
\hline & \multicolumn{2}{|c|}{ Repairable } & \multicolumn{2}{|c|}{ Irreparable } \\
\hline & Count & Row \% & Count & Row \% \\
\hline Full Crown & 6 & $60.0 \%$ & 4 & $40.0 \%$ \\
\hline E.max Endocrown & 2 & $20.0 \%$ & 8 & $80.0 \%$ \\
\hline CERASMART Endocrown & 7 & $70.0 \%$ & 3 & $30.0 \%$ \\
\hline
\end{tabular}

Table 2: Fracture mode (\%) in groups.

\section{Results}

One way ANOVA showed statistically significant differences between studied groups and post hock test showed significant differences between GP $(1301.34 \pm 177.12)$ and GE $(717.33 \pm 198.59)$ and between GE $(717.33 \pm 198.59)$ and GS $(1522.64 \pm 352.52)$ while between GP and GS there was no statistical significant difference.

The highest mean value of maximum load (Fracture resistance) was found in GS (CERASMART) $(1522.64 \pm 352.52)$ followed by GP (Fiber post) $(1301.34 \pm 177.12)$, the lowest mean value of maximum load (Fracture resistance) was found in GE (E.max) (717.33 \pm 198.59).

\section{Fracture mode}

The fracture patterns in group GP (IPS e.max CAD with fiber post and core retained crown):
In this group the most common pattern of fracture was fracture above the CEJ which recorded (60\% repairable) (Figures 2 and 4 ) and the fracture below the CEJ which recorded ( $40 \%$ irreparable).

The fracture patterns in group GE (IPS e.max CAD endocrown crown): In this group the most common pattern of fracture was below the CEJ which recorded the highest percentage of the fracture pattern (80\% irreparable), and the lowest percentage of the fracture pattern was recorded for the fracture pattern occurred above the CEJ $(20 \%$ repairable).

The fracture patterns in group GS (CERASMART endocrown crown): In this group the most common pattern of fracture was fracture above the CEJ which recorded the highest percentage (70\% repairable), and the lowest percentage fracture pattern was recorded for the fracture pattern occurred below the CEJ ( $30 \%$ irreparable). 
Citation: Al-shibri S, Elguindy J (2017) Fracture Resistance of Endodontically Treated Teeth Restored With Lithium Disilicate Crowns Retained With Fiber Posts Compared To Lithium Disilicate and Cerasmart Endocrowns: In Vitro Study. Dentistry 7: 464. doi: $10.4172 / 2161-1122.1000464$

Page 6 of 9

\section{Discussion}

Premolar teeth with extensive loss of coronal tooth structure have traditionally been restored by means of a cast metal or fiberglass reinforced composite post and Crown [12]. Concerns regarding such a procedure include the risk of root perforation and the need for removal of sound tissue in the root canal to facilitate the room for the post material, thus weakening the tooth-root complex. Moreover, the benefit of a post in the root canal for the overall retention of the successive reconstruction in general is being questioned in recent years [13].

Clinical results from long-term studies up to 17 years with crowns cemented on composite core build-ups have failed to demonstrate the merits of a metal post on the tooth survival in the presence of adequate ferrule effect $[14,15]$. The introduction and application of fiber reinforced composite posts has changed the view on the subject. The use of glass fiber posts has gained acceptance, particularly on premolars and anterior teeth. Their modulus of elasticity is similar to dentine, allowing better dissipation of masticatory loads through the tooth, which does not occur with cast metal posts [16]. The amount of remaining ferrule seems to be the predominant factor for tooth survival in extensively structurally compromised non-vital teeth [17].

Compared to other indirect restorative alternatives that may require root canal therapy, provision of an endocrown is a relatively easy, costeffective procedure that requires less chairside time, supragingival margins facilitate plaque control and clinical inspection [18]. In addition, endocrown allows minimal tooth reduction and thus strengthens the tooth, by preserving sound dental tissue and root canal structures [19].

Endocrown restorations seemed to eliminate the need for posts and buildups. For Several factors including the differences in configuration/design, thickness, and elastic moduli, less expansive, time saving and more practical that endocrowns have compared to conventional systems [20].

By avoiding the ferrule, which is typically found in conventional crowns and can be described as a 'bracing mechanism' of the restoration around the cervical tooth structure may cause the loss of sound enamel and dentin tissues that would be important for proper bonding of the restoration. In addition its reduce the need for macroretentive geometry, and provide a more esthetic result being constructed from ceramic [21].

Today, a large variety of CAD/CAM materials is available, from resin composite and silica-based ceramics to high-strength ceramics [22].

Though various machinable materials are available for all ceramic restoration using CAD/CAM systems, IPS e.max CAD block was selected in this study due to long term clinical success, stability and less laboratory steps, in addition the good bonding characteristic to the tooth structure as it etchable ceramic [23].

Hybrid materials have recently been introduced to the dental market and form a new class of CAD/CAM materials. The new hybrid ceramic CERASMART join the market since 2014, it's a nanoparticlefilled high-density composite resin, which contains $71 \%$ of filler particles by weight [24].

Since CERASMART has particular benefits such as less brittle and more flexible compared to conventional ceramics, fewer flaws and irregularities were observed, the possibility to modify or repair the surface easily and their stress absorbing properties, for all this advantages CERASMART were selected in this study on other hands the previous study didn't evaluated the mechanical performance of the hybrid ceramic CERASMART endocrowns in maxillary premolars [25].

The unique composition of CERASMART allows the material to have modulus of elasticity similar to that of dentin $(18 \pm 2 \mathrm{GPa})$ with $220 \mathrm{MPa}$ to $240 \mathrm{MPa}$ flexural strength, (150) which is slightly higher than feldspathic ceramics (151) Convectional ceramics in general are exhibited more rigidity with high flexural strength and flexural modulus, this material tend to be stronger but more brittle than hybrid ceramic, while hybrid ceramic exhibited high flexural strength and low flexural modulus to be less brittle and more flexible in order to absorb high stress loading [24-26].

In vitro testing was used because it over comes the many limitations associated with clinical testing such as individual variation by creating a controlled environment. These tests provide a guideline about the load bearing capacity of the different systems on prosthetic restoration like crowns may provide information that is closer to the clinical situation than testing material properties on standardized samples [27].

In this study, human teeth were used instead of bovine, metal or plastic teeth because of their bonding characteristics, thermal conductivity, modulus of elasticity and strength that closer to clinical situation [28]. Attention was paid to the selection of teeth with comparable sizes, in which the teeth were selected to be of approximate similarity in size and shape with $10 \%$ maximum deviation from the determined mean to eliminate any extreme variation for the maxillary premolars.

Posterior premolar teeth were used on previous studies $[9,21]$ showed non-satisfactory performance of premolar endocrowns in comparison to molar endocrowns in action of occlusal forces, and bond strength. This may be due to the smaller surface area of the pulp chamber and using restoration material with less bonding effect to the teeth.

Maxillary premolar teeth were chosen because the performance of premolar endocrowns with CERASMART hybrid ceramic may improve the bonding to the tooth structure and improve the flexure strength by the stress absorption ability as this not evaluated before in any previous study.

A specially designed centralizing device was used to embed the teeth vertically in the center of the epoxy resin blocks to ensure the position standardization. Teeth were embedded in epoxy resin $2 \mathrm{~mm}$ below the cemento enamel junction to mimic the position if the root in the bone. Epoxy resin was used as it modulus of elasticity (12 GPa) resemble that of the human bone $(18 \mathrm{GPa})$ [29]. All teeth were decapitated perpendicular to the long axis $2 \mathrm{~mm}$ coronal to the proximal CEJ in order to simulate the compromised condition of severely damage endodontically treated teeth premolars $[29,30]$.

Teeth were prepared according to clinically established preparation criteria for all ceramic endocrowns using a special milling machine to ensure standardization of the preparation [31,32]. The development of Cerec CAD-CAM systems and software offers several advantages in clinical practice.

First with the change in the grinding system from discs to a stepped cylindrical diamond bur and a cylindrical diamond with a tapered tip, the more flexible CAD-CAM shaping technique allows custom shaping 
Citation: Al-shibri S, Elguindy J (2017) Fracture Resistance of Endodontically Treated Teeth Restored With Lithium Disilicate Crowns Retained With Fiber Posts Compared To Lithium Disilicate and Cerasmart Endocrowns: In Vitro Study. Dentistry 7: 464. doi: $10.4172 / 2161-1122.1000464$

Page 7 of 9

and more precise milling of ceramic crowns. Furthermore, the adaptation of the inner surface of a restoration and the replication of the occlusal morphology are better [33].

Second endocrowns can be produced and seated in one appointment. Despite these advantages, there are clinical problems with the depth of the optical impression to record the crown, pulp chamber, and sometimes part of the canal [33].

The limited optical depth of Feld might result in a blurred image of the central retention cavity of the endodontic preparation if adjacent teeth limit the position of the camera head. With improvements in the intra-oral three-dimensional Omnicam camera CEREC 3D unit without need to use reflective medium making the capture images easier and faster, while the depth scale is extended to about $20 \mathrm{~mm}$ through "double triangulation", thereby, overcoming this limitation [34]. CEREC MC XL milling machine was used for all the restoration to insure standardization of the restorations.

A strict adherence to the bonding protocols for each material was followed according to the manufacture recommendations in order to eliminate variables during the bonding procedures.

The endocrowns were cemented using BisCem (Bisco Inc., Schaumburg, IL, USA) dual-cure adhesive resin cement as most of study [35-37] suggested that the resin cement provide chemical and micromechanical bonding to the tooth structure. The luting procedures followed the clinical total etch protocol to ensure a close simulation of clinically relevant conditions.

Combination between total etch combination between total etch and self-adhesive cement reported to increase the bond strength and provide high retention [38,39] in addition it acts as an inherent buffering layer that is able to absorb stresses during load application leading to increasing the fracture resistance values of the restoration [40].

Surface treatment of CERASMART all currently available in vitro studies found HF acid etching in combination with silane to be a superior pretreatment [41]. The application of HF acid partially dissolves the glass phase and provides undercuts in the micrometer scale for better micromechanical interlocking with a composite cement. However, the recently published working instruction of the International Academy for Adhesive Dentistry (IAAD) confirms the finding of the other laboratory studies and recommends pretreatment via HF acid etching and application of a silane $[41,42]$ The silica-based ceramic part of the hybrid ceramic seems to determine the best choice of surface pretreatment [43].

The samples testing was done by applying compressive load using a universal testing machine along the long axis of the endocrown using a load applicator in the form of stain less-steel round tip with a $3.4 \mathrm{~mm}$ diameter centered in occlusal surface between the buccal and lingual cusp with tin foil sheet in-between to achieve homogenous stress distribution and minimization of the transmission of local force peaks, at crosshead speed of $0.5 \mathrm{~mm} / \mathrm{min}$ until failure [29].

Compressive lading until fracture represented a worst-case scenario. It does not replicate what take place in the clinical oral environment, in which teeth are subjected to masticatory forces over a long period of time which may cause fatigue resulting in tooth fracture. However, this test would at least detect differences between different treatment modalities regarding their strength. This method of testing has been widely used in previous studies [44].
As regards to fracture resistance, the physiologic maximal occlusal force may vary up to $(500 \mathrm{~N})$ depending on facial morphology and age [45] study results of serval studies reported that mean loading force ranged between 222 to $445 \mathrm{~N}$ (average, $322.5 \mathrm{~N}$ ) in the premolar región [46,47]. In this study, the mean fracture loads for different tested groups were beyond the mean reported maximum masticatory forces. Therefore, it can be assumed that all the tested specimens could with stand the maximum intraoral posterior masticatory forces. The highest mean value of maximum load (Fracture resistance) was found in (CERASMART) $(1522.64 \pm 352.52)$ followed by (Fiber post) $(1301.34$ \pm 177.12), the lowest mean value of maximum load (Fracture resistance) was found in GE (E.max) (717.33 \pm 198.59).

Regarding to the design, the result obtained in this study showed that post and core with $2 \mathrm{~mm}$ ferrule effect supported IPS exam cad crown recorded a statistically significant higher mean value fracture load (1301.34 \pm 177.12$)$ than endocrowns made of IPS e.max (717.33 \pm 198.59), this probably due to smaller adhesion area of IPS e.max endocrown compared to post and core. On other hands, Schmidlin et al. [48] indicated the presence of ferrule effect witch distribute the stresses of the endodontically treated tooth.

Ma et al. [49] reported the value of ferrule which increases fracture strength and minimizes loss of bond of conventional all ceramic restorations.

This result were agreement with Lin et al. [50] and another study 9 who reported that the stress values on the enamel, dentin and luting cement for ceramic endocrown restorations were the lowest relative to conventional crown restorations supported with fiber posts and composite cores while smaller surface area of premolars for adhesion and the greater crown height, which compromises the mechanical properties of the endocrown.

This was opposed by Biacchi et al. [51] who reported that with the adhesive technique creating a sufficient ferrule might cause loss of tooth structure and result in compromised bonding strength, because enamel is preferred to dentine bonding, this contradictory finding might be related to the difference in the material and methodology between studies. Where Biacchi et al. used Rely X cement to perform their study rather than Biscem.

Regarding to the materials used for the fabrication of endocrowns with butt joint design, the result obtained in this study showed that endocrowns made of CERASMART recorded a statistically significant higher mean value fracture load $(1522.64 \pm 352.52)$ than endocrowns made of IPS e.max CAD $(717.33 \pm 198.59)$. This may be attributed to the boding strength of CERASMART to the tooth structure and stress absorption nature of hybrid ceramic composition with breaking energy (2.2 MPa) while the IPS e.max CAD has breaking energy (0.6 MPa). Moreover, due to the low Flexural Modulus of CERASMART (7.9 GPa) and high Flexural Modulus of e.max CAD (32.3 GPa) [24].

This results were in agreement with El-Damanhoury et al. [7] who reported significantly higher fracture resistance of hybrid ceramic endocrowns than IPS e.max CAD endocrowns.

This was opposed by Stona et al. [52] who reported that IPS Empress CAD and IPS e.max CAD showed higher fracture resistance compared with CEREC VITABLOCS Mark II. finding might be related to the difference in the material used in their study.

Regarding to the materials and design, the result obtained in this study recorded a non-statistically significant mean value fracture load between endocrowns with butt joint design made of hybrid ceramic 
Citation: Al-shibri S, Elguindy J (2017) Fracture Resistance of Endodontically Treated Teeth Restored With Lithium Disilicate Crowns Retained With Fiber Posts Compared To Lithium Disilicate and Cerasmart Endocrowns: In Vitro Study. Dentistry 7: 464. doi: $10.4172 / 2161-1122.1000464$

Page 8 of 9

CERASMART $(1522.64 \pm 352.52)$ and post and core with $2 \mathrm{~mm}$ ferrule effect supported IPS exam cad crown (1301.34 \pm 177.12$)$. This may be attributed to the bonding strength of CERASMART to the tooth structure and stress absorption nature of hybrid ceramic composition with breaking energy (2.2 $\mathrm{MPa}$ ) while the IPS e.max CAD has breaking energy (0.6 MPa) [24].

CERASMART endocrowns cemented with All- Bond (Bisco) resulted in higher fracture resistance than the controls. It must be considered that the adhesion of the restoration is dependent on the type of cement used moreover, it can be expected that the greater the adhesion of the restoration, the better the stress distribution within the system, thus resulting in higher fracture resistance. Not less important, premolars and molars may receive similar forces during oral function, contributing for the similar results when considering only posterior teeth [53]. Forberger et al. [54] endocrowns resulted in similar fracture strength when compared to groups restored with posts based on ceramic (zirconia), gold or glass fiber.

This result was opposed with by Lin et al. [46] observed the favorable performance of endocrown restorations in premolars over conventional crown by using the finite element method. These results were in agreement with Lin et al. [11], and Chang et al. [50] they found that the endocrown and conventional crown with post and core restorations for endodontically treated premolars did not significantly differ from each other. They explained that the endocrown restorations recorded comparable stress values because endocrown include both the crown and core as a single unit which decrease the effect of multiple interfaces that found in conventional crown. As well, thickening of the ceramic occlusal portion compared to the conventional crown.

This finding is clinically relevant because it shows that endocrowns may work similar to restorations made with intraradicular posts, at least concerning fracture resistance of posterior teeth. According to the previous discussion and result the first null hypothesis was rejected, since IPS e.max CAD endocrowns reveled low fracture resistance than IPS e.max CAD crowns retained with fiber posts and the composite core, while CERASMART endocrowns reveled higher but not statistically significant. While second null hypothesis was accepted, since endocrowns made of hybrid ceramics CERASMART material reveled more fracture resistance than IPS e.max CAD endocrowns.

\section{Conclusion}

Within the limitation of this study, the following conclusions were drawn:

- CERASMART endocrowns provide promising fracture resistance than IPS e.max CAD endocrowns as a treatment modality of endodontically treated maxillary premolars.

- CERASMART Endocrowns are as promising as fiber post and core supported IPS e.max CAD crowns interims of fracture resistance.

- Endocrowns made of IPS e.max CAD show lower fracture resistance than fiber post and core supported IPS e.max CAD crowns with irreparable.

- All fracture resistance loads obtained were far beyond the maximum masticatory forces, which can with stand the maximum intraoral masticatory forces in the maxillary premolar region.

\section{Recommendations}

In-vivo studies should be conducted to help the clinician predict the clinical performance of CERASMART endocrowns.

\section{Acknowledgements}

No acknowledgements

\section{Conflict of Interest}

No conflict of interest

\section{References}

1. Zhu Z, Dong XY, He S, Pan X, Tang L (2015) Effect of Post Placement on the Restoration of Endodontically Treated Teeth: A Systematic Review. Int J Prosthodont 28: 475-483.

2. Lazari PC, Oliveira RCN de, Anchieta RB (2015) Stress distribution on dentin-cement-post interface varying root canal and glass fiber post diameters. A three-dimensional finite element analysis based on microCT data. J Appl Oral Sci 21: 511-517.

3. Roscoe MG, Noritomi Y, Novais R, Soares J, Information RA (2013) Influence of alveolar bone loss, post type, and ferrule presence on the biomechanical behavior of endodontically treated maxillary canines》: Strain measurement and stress distribution.

4. Otto T (2004) Computer-aided direct all-ceramic crowns: preliminary 1year results of a prospective clinical study. Int J Periodontics Restorative Dent 24: 446-455.

5. Sagsen B, Aslan B (2006) Effect of bonded restorations on the fracture resistance of root filled teeth. Int Endod J 39: 900-904.

6. Tay FR, Pashley DH (2007) Monoblocks in root canals: a hypothetical or a tangible goal. J Endod 33: 391-398.

7. Rn HME, Platt HJA (2005) Fracture Resistance and Microleakage of Endocrowns Utilizing Three CAD-CAM Blocks. Oper Dent : 1-10.

8. Decerle N, Bessadet M, Eschevins C, Veyrune J, Nicolas E (2014) Evaluation of Cerec Endocrowns囚: A Preliminary Cohort Study 22: 1-7.

9. Bindl A, Mormann WH (1999) Clinical evaluation of adhesively placed Cerec endo-crowns after 2 years--preliminary results. J Adhes Dent 1: 255-265.

10. Goncalves LA d A, Vansan LP, Paulino SM, Sousa Neto MD (2006) Fracture resistance of weakened roots restored with a transilluminating post and adhesive restorative materials. J Prosthet Dent 96: 339-344.

11. Lin CL, Chang YH, Pai CA (2011) Evaluation of failure risks in ceramic restorations for endodontically treated premolar with MOD preparation. Dent Mater 27: 431-438.

12. Hayashi M, Takahashi Y, Imazato S, Ebisu S (2006) Fracture resistance of pulpless teeth restored with post-cores and crowns. Dent Mater 22: 477-485.

13. Magne P, Carvalho AO, Bruzi G, Anderson RE, Maia HP (2014) Influence of no-ferrule and no-post buildup design on the fatigue resistance of endodontically treated molars restored with resin nanoceramic CAD/CAM crowns. Oper Dent 39: 595-602.

14. da Silva GR, Santos-Filho PC de F, Simamoto-Jnior PC, Martins LRM, da Mota AS (2011) Effect of post type and restorative techniques on the strain and fracture resistance of flared incisor roots. Braz Dent J 22: 230-237.

15. D'Arcangelo C, De Angelis F, Vadini M, D’Amario M, Caputi S (2010) Fracture Resistance and Deflection of Pulpless Anterior Teeth Restored with Composite or Porcelain Veneers. J Endod. 36: 153-156.

16. Zhou L, Wang Q (2013) Comparison of Fracture Resistance between Cast Posts and Fiber Posts囚: A Meta-analysis of Literature. J Endod 39: 11-15.

17. Creugers NHJ, Mentink AGM, Fokkinga WA, Kreulen CM (2005) 5-year follow-up of a prospective clinical study on various types of core restorations. Int J Prosthodont 18: 1. 
Citation: Al-shibri S, Elguindy J (2017) Fracture Resistance of Endodontically Treated Teeth Restored With Lithium Disilicate Crowns Retained With Fiber Posts Compared To Lithium Disilicate and Cerasmart Endocrowns: In Vitro Study. Dentistry 7: 464. doi: $10.4172 / 2161-1122.1000464$

Page 9 of 9

18. Biacchi GR, Mello B, Basting RT (2013) The Endocrown: An Alternative Approach for Restoring Extensively Damaged Molars. J Esthet Restor Dent 25: 383-390.

19. Gresnigt MMM, Ozcan M, van den Houten MLA, Schipper L, Cune MS (2016) Fracture strength, failure type and Weibull characteristics of lithium disilicate and multiphase resin composite endocrowns under axial and lateral forces. Dent Mater 32: 607-614

20. Jotkowitz A, Samet N (2010) Rethinking ferrule-a new approach to an old dilemma. Br Dent J. 209: 25-33.

21. Skupien JA, Luz MS, Pereira-Cenci T (2016) Ferrule Effect A Metaanalysis. JDR Clin Transl Res.

22. Blatz MB (2002) Long-term clinical success of all-ceramic posterior restorations. Quintessence Int (Berl) 33: 6.

23. Guess PC, Schultheis S, Bonfante EA, Coelho PG, Ferencz JL (2011) Allceramic systems: laboratory and clinical performance. Dent Clin North Am. 55: 333-352.

24. Awada A, Nathanson D (2014) Mechanical properties of resin-ceramic CAD / CAM restorative materials. J Prosthet Dent. 2014: 1-7.

25. Alzayer AA (2016) Microleakage of lithium disilicate ceramic crowns and nano ceramic crowns: A comparative study.

26. Bhat V, Shenoy K, Dandekeri S, Reddy H (2016) CAD-CAM CERAMICS-A Litrature review.

27. Heydecke G, Peters MC (2002) The restoration of endodontically treated, single-rooted teeth with cast or direct posts and cores: a systematic review. J Prosthet Dent 87: 380-386.

28. Potocnik B (2015) Automated landmark points detection by using a mixture of approaches: the vole-teeth case. Signal, Image Video Process 9: 93-104.

29. Hamdy A (2015) Effect of Full Coverage, Endocrowns, Onlays, Inlays Restorations on Fracture Resistance of Endodontically Treated Molars 1: $1-5$.

30. Bassir MM, Labibzadeh A, Mollaverdi F (2013) The effect of amount of lost tooth structure and restorative technique on fracture resistance of endodontically treated premolars. J Conserv Dent 16: 413.

31. Coniglio I, Garcia-Godoy F, Magni E, Carvalho CA, Ferrari M (2009) Resin cement thickness in oval-shaped canals: oval vs. Circular fiber posts in combination with different tips/drills for post space preparation. Am J Dent 22: 290-294

32. Carvalho AO, Bruzi G, Anderson RE, Maia HP, Giannini M, Magne P (2016) Influence of adhesive core buildup designs on the resistance of endodontically treated molars restored with lithium disilicate CAD/CAM crowns. Oper Dent. 41: 76-82.

33. Guo J, Wang Z, Li X, Sun C, Gao E (2016) A comparison of the fracture resistances of endodontically treated mandibular premolars restored with endocrowns and glass fiber post-core retained conventional crowns. J Adv Prosthodont 8: 489 .

34. Lee CYS, Wong N, Ganz SD, Mursic J, Suzuki JB (2015) Use of an intraoral laser scanner during the prosthetic phase of implant dentistry: a pilot study. J Oral Implantol. 41: e126-e132.

35. Tian T, Tsoi JK-H, Matinlinna JP, Burrow MF (2014) Aspects of bonding between resin luting cements and glass ceramic materials. Dent Mater 30: e147-e162.

36. Pereira JR, Lins A, Shiratori K (2015) The effect of post material on the characteristic strength of fatigued endodontically treated teeth. J Prosthet Dent

37. Paul P, Duvvuri SNR, Alla RK, Rajasigamani K (2015) Evaluation of shear bond strength of stainless steel brackets bonded to ceramic crowns etched with Er; Cr: YSGG laser and hydrofluoric acid: an in vitro study. Br J Med Med Res 7: 550-560.

38. Spitznagel FA, Horvath SD, Guess PC, Blatz MB (2014) Resin bond to indirect composite and new ceramic/polymer materials: a review of the literature. J Esthet Restor Dent. 26: 382-393.

39. Ozer F, Blatz MB (2013) Self-etch and etch-and-rinse adhesive systems in clinical dentistry. Compend Contin Educ Dent 34: 12-14.

40. El Guindy J, El Sherif R, Aboul-Ezz AA (2016) Evaluation Of Marginal Discrepancy And Microleakage Of Lava Ultimate (Resin Nano Ceramic) Versus Lithium Disilicate (Ips E. Max Cad) Endocrowns. In Vitro Study. Indian J Sci Res 7: 27.

41. Lise DP, Van Ende A, De Munck J, Vieira L, Baratieri LN (2015) Microtensile Bond Strength of Composite Cement to Novel CAD/CAM Materials as a Function of Surface Treatment and Aging. Oper Dent 42 73-81.

42. Cekic-Nagas I, Ergun G, Egilmez F, Vallittu PK, Lassila LVJ (2016) Microshear bond strength of different resin cements to ceramic/glass-polymer CAD-CAM block materials. J Prosthodont Res 60: 265-273.

43. Güngör MB, Nemli SK, Bal BT, Ünver S, Doğan A (2016) Effect of surface treatments on shear bond strength of resin composite bonded to $\mathrm{CAD} / \mathrm{CAM}$ resin-ceramic hybrid materials. J Adv Prosthodont 8: 259-266.

44. Azarbal A (2015) Marginal Fit Comparison Of Cad/Cam Crowns Milled From Two Different Materials.

45. Lin CL, Chang YH, Chang WJ, Cheng MH (2006) Evaluation of a reinforced slot design for CEREC system to restore extensively compromised premolars. J Dent 34: 221-229.

46. Lin CL, Chang YH, Pa CA (2009) Estimation of the Risk of Failure for an Endodontically Treated Maxillary Premolar With MODP Preparation and CAD/CAM Ceramic Restorations. J Endod 35: 1391-1395.

47. Komiyama O, Obara R, Iida T (2015) Comparison of direct and indirect occlusal contact examinations with different clenching intensities. J Oral Rehabil 42: 185-191

48. Schmidlin PR, Stawarczy B, DeAbreu D, Bindl A, Ender A (2015) Fracture resistance of endodontically treated teeth without ferrule using a novel H-shaped short post. Quintessence Int (Berl) 46: 2.

49. Ma PS, Nicholls JI, Junge T, Phillips KM (2009) Load fatigue of teeth with different ferrule lengths, restored with fiber posts, composite resin cores, and all-ceramic crowns. J Prosthet Dent 102: 229-234.

50. Lin CL, Chang YH, Hsieh SK, Chang WJ (2013) Estimation of the failure risk of a maxillary premolar with different crack depths with endodontic treatment by computer-aided design/computer-aided manufacturing ceramic restorations. J Endod 39: 375-379.

51. Biacchi G, Basting R (2012) Comparison of Fracture Strength of Endocrowns and Glass Fiber Post-Retained Conventional Crowns. Oper Dent 37: 130-136.

52. Stona D, Burnett LH, Mota EG, Spohr AM (2015) Fracture resistance of computer-aided design and computer-aided manufacturing ceramic crowns cemented on solid abutments. J Am Dent Assoc 146: 501-507.

53. De Souza G, Braga RR, Cesar PF, Lopes GC (2015) Correlation between clinical performance and degree of conversion of resin cements: a literature review. J Appl Oral Sci 23: 358-368.

54. Forberger N, Göhring TN, Lang H (2008) Influence of the type of post and core on in vitro marginal continuity, fracture resistance, and fracture mode of lithia disilicate-based all-ceramic crowns. J Prosthet Dent 100 : 264-273. 